\title{
A Community Mental Health Approach in Identifying People at Risk of Poor Mental Health: A Case Study in Hong Kong
}

\author{
Joyce Lai Chong Ma1*, Chi Kan Wong2, Siu Kwong Tse ${ }^{2}$ \\ ${ }^{1}$ Department of Social Work, The Chinese University of Hong Kong, Hong Kong, China \\ ${ }^{2}$ Caritas Hong Kong, Hong Kong, China \\ Email: "joycelai@swk.cuhk.edu.hk
}

Received 13 August 2015; accepted 19 September 2015; published 22 September 2015

Copyright (C) 2015 by authors and Scientific Research Publishing Inc.

This work is licensed under the Creative Commons Attribution International License (CC BY). http://creativecommons.org/licenses/by/4.0/

c) (i) Open Access

\begin{abstract}
People with mental health needs are often reluctant to seek help due to inaccessibility to service and also stigmatization, especially in Chinese societies. However, professional effort to identify the high-risk people is inadequate. In this paper the authors described a five-year community-based outreaching project, which aimed at identifying the high-risk groups in seven deprived and lowincome communities territory wide and linking them up with mental health and social services. We assessed the project outcome by analysing the data (total number $=2181$ participants) gathered on-site using the 20-item Centre for Epidemiological Studies Depression Scale (CES-D). The results of our analysis have shown that the project had successfully identified the high-risk groups $(20.6 \%)$, with the following profile: the unemployed, housewife, the widowed and divorced and people with low education. They were referred to different services. The results of the post-intervention have indicated improved mental well-being of the participants who had received the services referred $(n=43)$. Our positive experience has confirmed the need of social workers to take an active role to reach out the unreachable, rather than be passive waiting them to come in.
\end{abstract}

\section{Keywords}

Community Approach, Mental Health, People at Risk, Case Study, Hong Kong

\section{Introduction}

Increased visibility and complexity of mental health problems in high stress societies such as Hong Kong indi-

*Corresponding author.

How to cite this paper: Ma, J. L. C., Wong, C. K., \& Tse, S. K. (2015). A Community Mental Health Approach in Identifying People at Risk of Poor Mental Health: A Case Study in Hong Kong. Advances in Applied Sociology, 5, 243-257. 
cates the distress people are experiencing. In the past two decades, our society has experienced economic turmoil brought about by the Asian Financial Crisis in 1998, the severe acute respiratory syndrome (SARS) crisis in 2003 and the Financial Tsunami in 2008. The territory's economy was badly affected especially in 2003 with the unemployment rate rising to 7.9\% (Census and Statistics Department, 2011). Besides unemployment (e.g., Paul \& Moser, 2009), long working hours (Lau, Ma, Wan, \& Lai, 2012), parental stress (Ma, Wong, Lau, \& Lai, 2011), health problems (Chi et al., 2005) and unanticipated loss (Li, Chan, \& Lee, 2002) may have negative impact on individuals; pileup effects of all these stressors would place people at high risk of poor mental health.

Although there is no large-scale epidemiological study investigating the prevalence of mental disorders in Hong Kong, it is estimated that about $15 \%$ to $25 \%$ of Hong Kong people have mental disorders of some kind, comparable to the rate in countries such as France (18.4\%), Australia (20.0\%) and USA (26.2\%) (Hospital Authority, 2011: 17).

Self-reported mental health condition of Hong Kong people was fair. A territory-wide telephone survey in 2006 found that around $10 \%$ of the respondents reported having poor or very poor mental health (Ma, Wong, Lau, \& Pun, 2007: 23). A Population Health Survey conducted in 2003/2004 $(\mathrm{n}=7084)$ has shown that $1.5 \%$ of the population aged 15 and above reported being diagnosed with depression (HKSAR Government, 2011). In reading the results of these studies, one has to be cautious of the possible biases due to respondents' underreporting or over reporting.

Unsurprisingly, people in society with fewer resources are vulnerable to experience hardship and stresses. A cross-sectional survey in 2002 found that new arrivals from Mainland, public housing residents and people with lower household income had poorer mental health (Wong et al., 2009). Ma et al.'s study (2007) revealed that lower educational attainment correlated with less satisfying physical and mental health, which in turn was associated with unhealthy perceived family functioning. The unemployed were likely to suffer from depression than the employed (HKSAR Government, 2011).

Women are twice as likely as men to be at risk of depression in the US (Kung, 2000). In Hong Kong, the prevalence rate of self-reported depression for women was $2.1 \%$ as compared to $0.7 \%$ for men; $1.9 \%$ of those aged 65 and $1.7 \%$ of those aged 55 - 64 suffered from depression as compared to $1.0 \%$ for the youth aged $15-24$ (Wong et al., 2009; HKSAR Government, 2011). Depression in older people is often associated with poor health, vision problems and higher level of impairment in activities of daily living (Chi et al., 2005) while women at child birth age are vulnerable to postnatal depression (Leung, Martinson, \& Arthur, 2005).

Unfortunately, not all people under great distress seek help, leaving the problem unattended and worsened. It is estimated that $36 \%$ American people with mental disorders were receiving treatment (Wang, Lane, Olfson, Pincus, Wells, \& Kessler, 2005). In the United Kingdom over half of people with serious depression received no treatment and only $8 \%$ had seen a psychiatrist (Layard, Clark, Knapp, Meacher, \& Priebe, 2006). The same is applicable to Chinese societies such as Hong Kong. In the face of economic difficulties, 56.7\% of Hong Kong respondents preferred seeking help from families, friends and relatives to receiving professional service (Siu, Wan, \& Wong, 2011).

A cultural perspective may shed light on a huge gap between people with mental health needs and those who access the service. In Chen and Mak's study (2008), compared to the European American, Chinese American and Mainland Chinese college students, Chinese college students in Hong Kong were more reluctant to seek help from mental health professionals. Variation of willingness in help seeking among the four groups of students can probably be attributable to the higher degree of westernization of the European American and the Chinese American students, and the customary practice of the Mainland students to be well taken care of by teachers and party leaders at school (Chen \& Mak, 2008). The general public may be more ill-informed, passive and avoidant of their psychological difficulties than college students since the latter has better knowledge, skills and resources in problem solving. It is therefore important for mental health professionals including social workers to actively reach out the high-risk groups and link them up with mental health services. Compact societies such as Hong Kong make active outreach easier.

The aims of this article are two-fold: 1) to describe a series of outreach service programmes (the programmes) carried out in Hong Kong from January 2006 to May 2010, which aimed to identify the high-risk people with depressive symptoms; and 2) to report the results of the data gathered on sites, which have identified the participants' characteristics and profile. In so doing, we have addressed the following two questions: Have the programmes achieved the service objective? If so, who were these high-risk groups? The evidence provided would serve as a base for advocacy of an active approach in helping people in need. 


\section{Literature Review}

\subsection{Mental Health Service in Hong Kong}

The number of people receiving help in the mental health service (number $=152,844$ ) in 2008 is lower than the estimated prevalence, which ranges from 1.17 million $(15 \%)$ to 1.95 million $(25 \%)$, of the total population (number $=7.8$ millions) (Hospital Authority, 2011: 19). The disparity indicates that a large number of people's problem remain unidentified in the community.

Similar with experiences of western countries such as the USA (USA Public Health Service, Office of the Surgeon General, 1999) and the UK (Layard et al., 2006), people with serious mental illnesses such as schizophrenia disorder and dementia have consumed most of resources in Hong Kong mental health service; little public funding is left for early identification and early detection especially for those with mild to moderate psychological distress. Programmes on early identification of those with serious mental illnesses were organized and expanded. For example, the Early Assessment Service of Young Persons with Psychosis (EASY) was piloted in 2001 to address the need of young people aged 15 - 25 who have developed an early psychosis (Hospital Authority, 2011: 28, 44); similar service was to be expanded to adults. While our policy makers have increasingly recognized the importance of early identification and early intervention for people with mental illnesses, the current approach to community mental health is predominantly passive and reactive in nature; needs of those suffering from mild to moderate psychological distress are often overlooked.

For those people referred to mental health service, problems such as manpower shortfall, inaccessibility and fragmentation of our mental health services have been expressed in the past. Treatment delay is not uncommon due to long waiting time to first attendance; insufficient follow-up; inadequate and heavy workload of mental health professionals; lack of knowledge on patients' service satisfaction, effectiveness of preventive programs and experience of patients and careers (Hospital Authority, 2011; Legislative Council, 2011); all these account for drop-out from the service. In response to the growing criticisms, the Hospital Authority has reviewed its treatment policy for people with mental illnesses and proposed policy strategies to improve service utility. Limited by its authority and mandate, the review has been confined to services provided by the Hospital Authority. No review has been made on the interface between mental health and social services. There is a lack of long-term mental health policy governing future direction of service development, which ultimately aims to foster better mental health of people in Hong Kong.

\subsection{Barriers to Mental Health Service}

Several factors account for under-utilization of our mental health service, namely social stigma attached to the illness (Scheyett, 2005), people's perception of mental illness, cultural emphasis of self-reliance in problem solving and self-restraint in emotional management of Chinese (Tseng, Lin, \& Yeh, 1995) in the face of hardship and adversity in life.

Social stigma attached to mental illnesses is a barrier hindering those in need from utilizing mental health services in USA (Scheyett, 2005). A study of perceived stigmatization of half-way house residents diagnosed with schizophrenia disorder found that over half felt that their family disliked or despised them. Close to $60 \%$ said that their families considered them as highly violent. Over half of the respondents hid their illness from their friends, co-workers or classmates (Lee, Lee, Chiu, \& Kleinman, 2005).

People's perception of mental problems also affects their help-seeking behaviors (Chen \& Mak, 2008). Mental problems are perceived as personal failures and disclosing their problem to others is shameful and losing face (Chung \& Wong, 2004). People choose to present it as a health problem, which is less stigmatizing than a mental disorder.

Chinese Confucian culture of emphasizing personal and social harmony has negatively influenced people's view on mental illness, since mental illness is often associated with unpredictability, uncontrollability and violent behaviors. According to the rule of golden mean, zhongyong (中庸), a virtuous person should be calm and avoid being volatile in emotional expression in order to be strong and respected. Honest expression of one's emotionality is a sign of weakness in the eyes of others (Tseng, Lin, \& Yeh, 1995).

Folk beliefs, such as the onset of a mental illness is the consequence of the ancestor's misconduct and the god's punishment, are common among people with lower educational attainments. Having a family member suffering from a mental illness is a disgrace and shame of the whole kinship, jiazhu (家族) (Yang, 2007). These 
cultural beliefs are another barrier for people to acknowledge their mental health needs and seek treatment. Chen and Mak's study (2008) has indicated the cultural hurdle in help-seeking. Chinese college students from Hong Kong and Mainland China were less willing to seek professional help when compared to European and Chinese American college students (Chen \& Mak, 2008). The elderly was even more hesitant than the younger generation in help-seeking (Ye, Leung, \& Mok, 2011).

Despite limited public funding in early detection and intervention, mental health professionals in Hong Kong have launched a 4-year multilevel pilot community programme, the Defeat Depression Project, from 1999 to 2003, for residents and health-care professionals living in a district to educate them about depression as a mental illness, and its prevention and treatment, and to provide evidence-based information and sharing of skills to family doctors and health-care professionals (Leung \& Cheung, 2004). The project outcome is positive as indicated by the service users' better symptom knowledge, their readiness to seek professional help and the increased number of new cases with depression seeking treatment. However, the impact of the project was limited by its service catchment area and the lack of sustainability.

In view of a huge service gap between people with mental health needs and those who are willing to seek help in Hong Kong, there is a great need for social workers to launch a long-term community-based programme to reach out to the high-risk groups whose pain and suffering are invisible and unknown to mental health services.

\section{Outreaching Community Mental Health Programmes}

\subsection{Conceptualization of the Programmes}

We conceptualized our programmes on the basis of Caplan (1964)'s model of community mental health prevention. The level of prevention is roughly defined by the intervention timing and the goals of prevention. The primary level focuses on reducing the rate of new cases of the whole population; the secondary level emphasizes on early detection at the early stage of illness in order to reduce the development of serious illness; and tertiary prevention aims to prevent relapse and ameliorate the disability of those who are already seriously ill in the community and are under psychiatric care and rehabilitation to restore their optimal level of social functioning. Our project focused on fostering the interface between primary prevention under which identifying high-risk groups has become the paramount concern and secondary prevention whereby provision of timely help to meeting their mental health needs would reduce the incidence of mental breakdown.

Guided by a strengths-oriented perspective (Sousa, Ribeiro, \& Rodrigues, 2006), social workers believe that people with mental health needs are capable of making rational choices in help-seeking if resources are available. People with mental health needs have failed to seek help probably because of different socio-cultural barriers (e.g., stigma and perception of mental health problems). Sympathetic listening by lay people with mental health needs and sharing of their experiential knowledge (Nayar, Kyobutungi, \& Razum, 2004) may help to reduce the barriers to help seeking and provide momentum for the needy to deal with their problems directly. A supportive network, both formal and informal, is a key social capital that has been shown to moderate distress, sense of loss and social isolation in deprived and low-income communities in East London (Cattell, 2001); the literature has reminded mental health professionals the potential value of collaborating with lay people in helping. To what extent is this strategic alliance applicable to Hong Kong?

In brief, the design and development of our outreach programmes are essentially based on our beliefs of the strengths of people with mental health needs (Sousa, Ribeiro, \& Ridrigues, 2006), mutual help and mutual support (Nayar, Kyobutungi, \& Razum, 2004), the significant role played by social support in empowering them and reducing their sense of isolation (Cattell, 2001), and most importantly the genuine care and concern of the social workers toward their pain and sufferings.

\subsection{Partnership among the Social Service Agency, Social Work Academic, and Mental Health Professionals}

This project grew out of a brainstorming discussion among the first author, a university academic, the second and the third authors, supervisors of the Caritas Community Development Service (the Caritas, hereafter) in 2005. Social workers of Caritas have been working with poor and deprived communities for decades in grassroot organization and locality development. The first author was primarily responsible for conceptualizing the service programmes, offering staff training and assessing the programme outcome. From 2006 to 2010 a total of 
24 training sessions (total 73 hours) were organized in the university, aiming to equip the social workers with evidence-based knowledge and skills in helping people at risk of poor mental health. The training content covered topics such as identification of different mental health problems, crisis management and family engagement. Besides, a private-sector psychiatrist helped to deliver training particularly on assessment of mental health problems and crisis management. Being the team leaders of the service, the second and the third authors provided supervision, guidance and advice to the social workers, in addition to soliciting funding support and monitoring the programmes.

The social workers had recruited the core members of the self-help groups for people with mild to moderate depression, who have been actively coping with their problems and difficulties, in their service centres to be mental health ambassadors (the ambassadors). Training was provided to the ambassadors on: 1) active listening skills; 2) interpersonal sensitivity; 3) principles of experiential sharing; and 4) community resources.

\subsection{Programme Objectives and Programme Design}

The objectives of our programmes were primarily to: 1) identify the individuals with mild to moderate level of depression in the community in a culturally acceptable way and link them with mental health or social services; and 2) train the ambassadors to provide mutual help and mutual support to the high risk people in the community. Figure 1 shows the flow of our programmes, which comprised onsite educational seminars, exhibition on mental health, physical and mental health check-up and peer and professional counselling. Free onsite physical health check-up (namely test on blood glucose level and cholesterol level) was employed to attract more with participants because people seemed to be more concerned with their physical health than their psychosocial well-being. Besides, it is less stigmatizing in the perspective of the participants. After physical check-up, participants were invited to join the mental health check-up too.

\subsection{Screening Measure}

Participants' level of depression was screened by a 20-item of Centre for Epidemiological Studies Depression Scale (CES-D) (Radloff, 1977). Participants were asked to fill in the self-reporting 4-point Likert scale (seldom/ none $=0$, rarely $=1$, sometimes $=2$, often $=3$ ) on a voluntary basis. CES-D was found to be valid and reliable (Cronbach's alpha $=0.883$ ) in identifying depressed individuals in American and Chinese societies (Radloff, 1977; Cheung \& Bagley, 1998). Index of CES-D was formed by adding the scores of the 20 items, with higher scores denoting higher level of depression; the scale ranged from 0 to 60 , with the cut-off point at 15; participants who scored less than 15 points indicate mentally healthy. Those who scored from 15 to 21 are experiencing some mild to moderate symptoms of depression; those who scored over 21 denoted experiencing a high level of depressive symptoms associated with major depression (Radloff, 1977). Individual total score was calculated immediately after completion of the questionnaire.

Social workers and the ambassadors carried out the programmes together. Besides participating in the preparatory meetings for the programs, the ambassadors had actively helped to promote the programme in the community, assisted the participants to fill in the CES-D questionnaire, and most importantly shared their positive experience with the participants and encouraged them to seek help during the onsite counselling. In counselling the social worker was the case manager while the ambassador was a resourceful peer. With the permission of the partici-

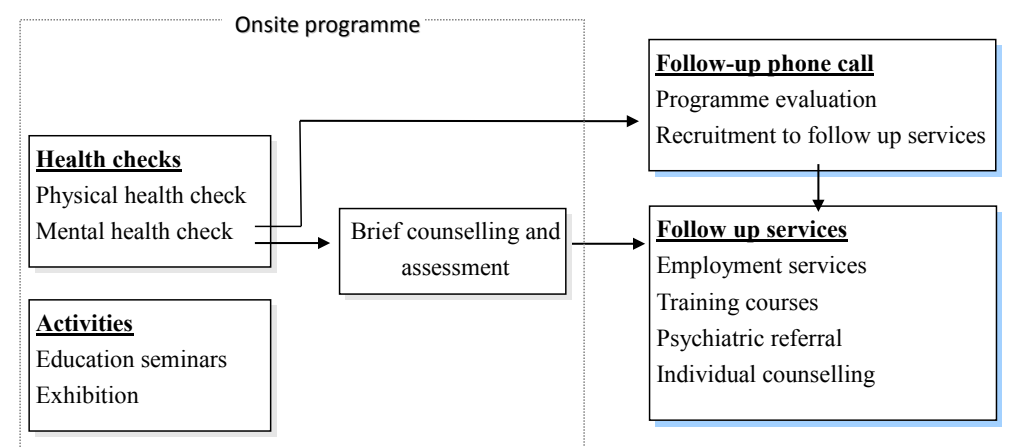

Figure 1. Programme flow. 
pants, the ambassador would call the participants afterward to express their care and concern and render support, if needed. The ambassadors were invited to meet the funders as well as participate in press conferences to share how they had benefited from the programme.

Counselling services were also arranged for those who scored below 15 but still wanted to meet the social workers and the ambassadors. Follow-up services included employment assistance services (e.g., job placement and job re-training), psychiatric referral, short training courses (such as stress coping and parental education course) and counselling services were provided. For those who had not met the social worker, they were contacted after the programmes for follow-up action if they had left their contact number.

In fact, all of the participants whom we had in contact with were asked to give their telephone number to our social workers, if they were willing. Follow-up phone calls were made within two weeks after the programmes were held to see whether they found the programme useful in heightening their awareness on the importance of mental health and improving knowledge in this area. The social worker encouraged them to use the services provided by the agency and explored if their service needs have been met by the referral/s.

\subsection{Community Served}

In the past five years our social workers had conducted 33 outreach programmes in 7 communities. The programmes were initially carried out in urban areas in 2006 and were expanded to rural communities two years later. A total of 25 outreach programmes were carried out in urban areas and the remaining 8 were in rural areas. Selection of these communities was predominantly based on information provided by the Census (HKSAR Government, 2006) with the following criteria: old urban communities and rural slums with higher percentage of low-income families, single-parent families and new immigrants living there. For programmes held in the urban areas, booths were set up on sites near large public housing estates or inside shopping malls. People passing by were invited to join the programmes. For programmes held in rural communities where the population was less dense, they were held at the agency centre. The social workers promoted the programmes through home visits and distribution of promotional leaflets.

\section{Methodology}

The project outcome was assessed through data collection of the following areas: 1) socio-demographic characteristics of the participants (e.g., age, sex, education, income); 2) the participants' level of depression, which was measured by CES-D (Radloff, 1977) as described above; 3) problems and concerns that have been bothering the participants; 4) perceived helpfulness of the programmes, which was measured by two items, with the first question "Did the programmes help to increase your mental health knowledge?" and the second "Did the programmes help to heighten your awareness on mental health?" The participants were asked to respond on 'yes' or "no"; and 5) numbers of referrals made to psychiatric service, counselling service, emotional management class, job retraining and others (e.g., referral for welfare subsidy).

The effect of the referred services on the participants was assessed as followed: 1) we have invited a total of 211 participants who have received the services provided by the agency to participate in the focus group interview or individual interview conducted by the social workers from October 2012 to December 2012; 2) they were asked to respond to the CES-D (Radloff, 1977) in the post-intervention phase. We have lost contacted of 168 participants $(79.8 \%)$ and 43 participants $(20.4 \%)$ turned up for the post-intervention interview, with 12 attending the focus-group interview and 31 attending the individual interview.

\subsection{Data Analysis}

Descriptive data such as the socio-demographic characteristics of the participants, the numbers of referrals made to different mental health and social services, perceived helpfulness of the programmes were summarized by percentage and frequencies. We calculated the mean score of the CES-D (Radloff, 1977); using 15 as the cutting point to group the participants into three groups: a) the high-risk group, that is, those who scored 21 or above; b) the mild to moderate group, that is, those whose CES-D score was 15 to 20 and c) the low-risk group, that is, those who scored below 15. The effect of the socio-demographic characteristics on the level of depression was first analysed by Chi-square using the bi-variate analysis and subsequently the binary logistic regression with depression score as dependent variable (CES-D scored 15 or above $=1$, CES-D scored below $15=0$ ) and the socio-demographic characteristics as the independent variables. The mean score of the CES-D gathered from the 
onsite program was compared with the mean score of the CES-D collected after the provision of the referred services using paired t-test to assess if there is any significant difference between the two mean scores.

\subsection{Profile of the Participants}

Table 1 listed the profile of the participants. Generally speaking, higher percentage of women than men participated in our programmes. The majority of the participants were in middle adulthood (44 - 50) and late adulthood

Table 1. Profile of the respondents.

\begin{tabular}{|c|c|}
\hline & Overall (\%) \\
\hline \multicolumn{2}{|l|}{ Sex } \\
\hline Male & 23.5 \\
\hline Female & 76.5 \\
\hline (n) & $(2181)$ \\
\hline \multicolumn{2}{|l|}{ Age } \\
\hline$<30$ & 9.8 \\
\hline $31-40$ & 20.0 \\
\hline $41-50$ & 32.5 \\
\hline $51-64$ & 37.7 \\
\hline (n) & (2108) \\
\hline \multicolumn{2}{|l|}{ Educational attainment } \\
\hline Primary & 28.6 \\
\hline Junior Secondary & 42.9 \\
\hline Senior Secondary & 21.3 \\
\hline Post Secondary & 7.2 \\
\hline (n) & $(1885)$ \\
\hline \multicolumn{2}{|l|}{ Marital status } \\
\hline Single & 13.1 \\
\hline Married & 76.7 \\
\hline Divorced/widowed & 10.2 \\
\hline (n) & (1938) \\
\hline \multicolumn{2}{|l|}{ Working status } \\
\hline Employed & 49.7 \\
\hline Unemployed & 9.6 \\
\hline Homemaker & 37.1 \\
\hline Retired & 3.6 \\
\hline (n) & $(2081)$ \\
\hline \multicolumn{2}{|l|}{ Place of recruitment } \\
\hline Urban & 80.3 \\
\hline Rural & 19.7 \\
\hline (n) & $(2181)$ \\
\hline
\end{tabular}


$(51-64)$ with primary and secondary educational level. As the programmes were initially implemented in urban communities, over $80 \%$ of participants came from the urban communities and the rest of the participants came from rural communities.

All of the 43 participants $(97.7 \%)$ who had participated in the post-intervention interview were female, except one (2.3\%); 19 (44.2\%) participants' age ranged from $35-45,15(34.9 \%)$ aged 46 to 55 and $6(13.9 \%)$ aged 56 to $65 ; 3(6.9 \%)$ aged $30-35.58 .1 \%$ of participants had received either primary school education $(\mathrm{n}=25)$ or secondary school education $(n=18 ; 41.9 \%)$. The majority of them $(n=32 ; 74.4 \%)$ were married; $7(16.3 \%)$ were single-parent families while 4 (9.3\%) remained single. Eleven $(25.6 \%)$ of them were housewives and $3(6.9 \%)$ of them were unemployed. Among the employed, 18 (41.9\%) participants' income ranged from HK\$7000 (USD897) to HK\$8000 (USD1025.6), 7 below HK\$7000 (USD897), indicating that their income was low. Four $(9.3 \%)$ participants were welfare recipients.

The social workers have involved a total of 31 ambassadors in this project, with an average of 8 to 10 ambassadors participating in each of the on-site out-reaching programmes. These ambassadors came from low-income families or were receiving the welfare subsidy provided by the government. Their average age was 45 ; over $80 \%$ were female with low education attainment.

\section{Results of the Study}

Pooling the data from 5 years, it was found that, by and large, 20.5\% of the participants scored 15 - 21, denoting mildly depressed; $20.6 \%$ of the participants scored over 21 , which indicated severe depressive symptoms. The remaining $58.8 \%$ scored below 15 . The mean score was 15.37 , which was slightly higher than the cut-off point (Table 2).

Cross-tabulation was performed to see whether the CES-D scores were different by sex, age, educational attainment, marital status, working status, place of recruitment. The results of the analysis have shown that female were more likely to report higher scores than male. Higher percentage of those aged 31 to 41 scored more than 21 as compared to those aged 41 to 50 , aged less than 30 and aged 51 to 64 . The unemployed were more likely to be severely depressed as compared to the employed, homemakers, and the retired. Those who were single and married were also more likely to be mentally healthy than the widowed or divorced. Some $21.7 \%$ and $21.9 \%$ of the participants recruited in rural areas scored $15-21$ and 22 points or above respectively, a percentage higher than those recruited urban areas (Table 2).

For those who scored 15 or above in CES-D (Radloff, 1977), many expressed concerns over relationships with family members (parent-child relations: 26.9\%; spousal relations: $25.3 \%$; problems of getting along with family: $11.3 \%$ ), followed by work-related and financial problems (economic pressure: $24.9 \%$; work/retirement/ unemployment: $17.3 \%$ ) (Table 3). Physical health of the participants and their family were another major concern $(22.5 \%)$. Other problems faced by the participants included adaptation to society $(9.6 \%)$ and death of family member $(3.6 \%)$.

Table 4 presented the follow-up services provided to the participants. About $30.2 \%$ of the high-risk group, that is, those participants with the CES-D scored 15 or above, were referred for counselling service; $46.0 \%$ joined the emotional management class and 5.0\% for psychiatric service. It is noted that $38.9 \%$ and $47.2 \%$ of the low-risk group (that is, those CES-D scored below 15) were referred for counselling service and emotional management class as well.

About $88.1 \%$ of participants perceived the programmes helpful in increasing mental health knowledge; $85.7 \%$ had heightened their awareness in mental health (Table 5) but $11.3 \%$ and $14.3 \%$ perceived unhelpful in both areas.

However, the results of the bivariate analysis were limited by the fact that the effect of the selected variable such as educational attainment might be confounded by other socio-demographic variables. In view of such limitation, binary logistic regression would be carried out to rule out the confounding effects of other variables.

We then examined the independent effect of socio-demographic variables by running binary logistic regression with depression score as dependent variable (CES-D scored 15 or above $=1$, CES-D scored below $15=0$ ) and the results were shown in Table 6. Employment seemed to be a protective factor: the unemployed (exp $(\beta)$ $2.198,2.259$ and 2.159$)$ and homemakers $(\exp (\beta) 1.447,1.436$ and 1.457) were more likely to be depressed than the employed in model 1 to 3 ; this was also the case for the retired in model 2 and $3(\exp (\beta) 1.816$ and 1.829). Those who were widowed and divorced were also more likely to have a higher scored than those who 
Table 2. Depression score (CES-D) by socio-demographic characteristics of the participants.

\begin{tabular}{|c|c|c|c|c|c|}
\hline & \multicolumn{3}{|c|}{ CES-D (\%) } & \multirow{2}{*}{ (n) } & \multirow{2}{*}{ Mean $(\mathrm{sd})^{2}$} \\
\hline & Below 15 & $15-21$ & 22 or above & & \\
\hline Overall $^{1}$ & 58.8 & 20.5 & 20.6 & $(2181)$ & $15.37(0.48)$ \\
\hline \multicolumn{6}{|l|}{ Sex } \\
\hline Male & 63.7 & 19.5 & 16.8 & $(512)$ & $15.31(0.46)$ \\
\hline Female & 57.3 & 20.9 & 21.8 & $(1669)$ & $15.39(0.49)$ \\
\hline \multicolumn{6}{|c|}{$\left(\chi^{2}=7.774, \mathrm{df}=2, p<0.05\right)$} \\
\hline \multicolumn{6}{|l|}{ Age } \\
\hline$<30$ & 60.9 & 20.3 & 18.8 & $(207)$ & $15.36(0.48)$ \\
\hline $31-41$ & 53.2 & 20.4 & 26.4 & $(421)$ & $15.44(0.50)$ \\
\hline $41-50$ & 58.7 & 20.6 & 20.7 & $(686)$ & $15.36(0.48)$ \\
\hline $51-64$ & 61.6 & 20.8 & 17.6 & (794) & $15.33(0.47)$ \\
\hline \multicolumn{6}{|c|}{$\left(\chi^{2}=14.003, \mathrm{df}=6, p<0.05\right)$} \\
\hline \multicolumn{6}{|l|}{ Educational attainment } \\
\hline Primary & 54.8 & 21.9 & 23.3 & $(540)$ & $15.40(0.49)$ \\
\hline Junior secondary & 59.8 & 19.6 & 20.7 & $(808)$ & $15.36(0.48)$ \\
\hline Senior secondary & 57.0 & 19.9 & 23.1 & $(402)$ & $15.39(0.49)$ \\
\hline Post secondary & 59.3 & 23.7 & 17.0 & $(135)$ & $15.36(0.48)$ \\
\hline \multicolumn{6}{|c|}{$\left(\chi^{2}=5.839, \mathrm{df}=6, \mathrm{~ns}\right)$} \\
\hline \multicolumn{6}{|l|}{ Marital status } \\
\hline Single & 55.7 & 20.2 & 24.1 & $(253)$ & $15.40(0.49)$ \\
\hline Married & 61.5 & 20.5 & 18.0 & $(1487)$ & $15.34(0.47)$ \\
\hline \multirow[t]{2}{*}{ Others } & 42.9 & 17.2 & 39.9 & (198) & $15.55(0.50)$ \\
\hline & \multicolumn{3}{|c|}{$\left(\chi^{2}=52.661, \mathrm{df}=4, p<0.001\right)$} & & \\
\hline \multicolumn{6}{|l|}{ Working status } \\
\hline Employed & 63.5 & 17.7 & 18.8 & $(1035)$ & $15.33(0.47)$ \\
\hline Unemployed & 43.7 & 23.6 & 32.7 & (199) & $15.53(0.50)$ \\
\hline Homemaker & 55.6 & 23.8 & 20.6 & $(772)$ & $15.39(0.49)$ \\
\hline \multirow[t]{2}{*}{ Retired } & 56.0 & 22.7 & 21.3 & (75) & $15.39(0.49)$ \\
\hline & \multicolumn{3}{|c|}{$\left(\chi^{2}=37.539, \mathrm{df}=6, p<0.001\right)$} & & \\
\hline \multicolumn{6}{|l|}{ Place of recruitment } \\
\hline Urban & 56.4 & 21.7 & 21.9 & $(1751)$ & $15.39(0.49)$ \\
\hline Rural & 68.8 & 15.8 & 15.3 & $(430)$ & $15.27(0.44)$ \\
\hline \multicolumn{6}{|c|}{$\left(\chi^{2}=22.199, \mathrm{df}=2, p<0.001\right)$} \\
\hline
\end{tabular}

${ }^{1}$ Index was formed by adding the scores of the 20 CES-D indicators. Overall Cronbach's alpha of CES-D is 0.883 (2006: 0.887, 2007: 0.868, 2008: 0.874, 2009: 0.881, 2010: 0.888). ${ }^{2}$ Index ranged from 0 to 60 . 
Table 3. Problems faced by the depressed participants (CES-D score $>14$ ).

\begin{tabular}{cc}
\hline Parent-child relations & $(\%)^{1}$ \\
Economic pressure & 26.9 \\
Spousal relations & 25.3 \\
Health problem (self/family) & 24.9 \\
Traditional value-related & 22.5 \\
Lack of emotional support & 22.9 \\
Work/retired/unemployment & 19.7 \\
Problems of getting along with family & 17.3 \\
Adaptation (new immigrant) & 11.2 \\
Family pass away & 9.6 \\
(n) & 3.6 \\
\hline
\end{tabular}

${ }^{1}$ Allow multiple responses; sum of percentage may be greater than $100 \%$.

Table 4. Follow-up service provided (\%).

\begin{tabular}{lcc}
\hline & CES-D: below 15 & CES-D: 15 or above \\
\hline 1. Referral: psychiatric service & 1.4 & 5.0 \\
2. Referral: counselling service & 38.9 & 30.2 \\
3. Emotional management class & 47.2 & 46.0 \\
4. Employment registration/job training & 4.2 & 4.3 \\
5. Program for re-entry to society & 1.4 & 2.2 \\
Others & 0.0 & 5.0 \\
2 and 3 & 4.2 & 6.5 \\
2 and 5 & 1.4 & 0.7 \\
(n) and 5 & 1.4 & 0.0 \\
\hline
\end{tabular}

Table 5. Evaluation of the programme (\%) (CES-D score > 14).

\begin{tabular}{cccc}
\hline & Helpful & Not helpful & (n) \\
\hline Improve knowledge in mental health & 88.1 & 11.9 & $(260)$ \\
Increase awareness of mental health & 85.7 & 14.3 & (259) \\
\hline
\end{tabular}

were single in model 1 to $3(\exp (\beta) 1.592,1.622$ and 1.680). As for the educational level, those who attained primary educational level only were more likely than those who attained junior secondary educational level to scored 15 or above in all the models. Sex and age exerted no independent effect on the depression score.

Table 7 has indicated the participants did benefit from the services provided (Table 8). Before the intervention, the mean score of the participants' CES-D was 29.26, with its score ranging from 52 to 17 ; in the post-intervention phase the mean score of CES-D had lowered to 18.95 , with its range from 42 to 1 . The difference in the two mean scores of CES-D was statistically significant. The participants had become emotionally more stable and reported improved coping (Table 9). 
Table 6. Logistic regression of depression score $(\mathrm{CES}-\mathrm{D})(\operatorname{Exp}(\beta))$.

\begin{tabular}{|c|c|c|c|}
\hline & Model 1 & Model 2 & Model 3 \\
\hline Female & 1.122 & 1.024 & 1.024 \\
\hline \multicolumn{4}{|l|}{ Age $(<30)$} \\
\hline $31-41$ & 1.227 & 1.246 & 1.232 \\
\hline $41-50$ & 1.121 & 1.170 & 1.159 \\
\hline $51-64$ & 0.852 & 0.887 & 0.868 \\
\hline \multicolumn{4}{|c|}{ Educational attainment (Primary) } \\
\hline Junior secondary & $0.681^{* *}$ & $0.643^{* * *}$ & $0.662^{* *}$ \\
\hline Senior secondary & 0.810 & 0.765 & 0.757 \\
\hline Post secondary & 0.786 & 0.708 & 0.714 \\
\hline \multicolumn{4}{|l|}{ Marital status (single) } \\
\hline Married & 0.758 & 0.773 & 0.792 \\
\hline Others & $1.592^{*}$ & $1.622^{*}$ & $1.680^{*}$ \\
\hline \multicolumn{4}{|c|}{ Working status (employed) } \\
\hline Unemployed & $2.198^{* * *}$ & $2.259^{* * *}$ & $2.159^{* * *}$ \\
\hline Homemaker & $1.447^{* *}$ & $1.436^{* *}$ & $1.457^{* *}$ \\
\hline Retired & 1.762 & $1.816^{*}$ & $1.829^{*}$ \\
\hline \multicolumn{4}{|c|}{ Recruitment place (urban) } \\
\hline Rural & - & $0.569^{* * *}$ & $0.559^{* * *}$ \\
\hline \multicolumn{4}{|l|}{ Year (2006) } \\
\hline 2007 & - & - & $0.473^{* * *}$ \\
\hline 2008 & - & - & $0.608^{*}$ \\
\hline 2009 & - & - & $0.608^{*}$ \\
\hline 2010 & - & - & $0.461^{* * *}$ \\
\hline Nagelkerke R-sq & 0.051 & 0.066 & 0.084 \\
\hline (n) & $(1609)$ & (1609) & (1609) \\
\hline
\end{tabular}

Dependent variable: $1=15$ or above, $0=$ below $15 .{ }^{*} p<0.05,{ }^{* *} p<0.01,{ }^{* * *} p<0.001$.

Table 7. CES-D score before and after intervention (total no of participants $=43$ ).

\begin{tabular}{cc}
\hline & Mean (s.d.) \\
\hline Before intervention & $29.26(1.61)$ \\
After intervention & $18.95(1.69)$ \\
$t$-value (paired $t$-test) & $4.887^{* * *}$ \\
\hline
\end{tabular}
${ }^{* * *} p<0.001$.

Table 8. Services provided.

\begin{tabular}{lc}
\hline & $(\%)^{1}$ \\
\hline Referral: psychiatric service & 9.3 \\
Referral: counseling service & 60.5 \\
Emotional management class & 32.6 \\
Employment registration/job training & 14.0 \\
$(\mathrm{n}=43)$ & \\
\hline
\end{tabular}

${ }^{1}$ More than one service was attended by some of the clients. Percentages may not add up to $100 \%$. 
Table 9. Participants' feedback on their current situation (total no. of participants $=43$ ).

\begin{tabular}{cc}
\hline & Frequency \\
\hline Got full-time or part-time job & 10 \\
Become emotionally more stable & 17 \\
Improve in coping & 10 \\
$\begin{array}{c}\text { (e.g., do exercise, join community activities, learn to seek help instead } \\
\text { of keeping it to oneself, able to manage stress under stressful working environment) } \\
\text { Still receiving psychiatric services } \\
\text { Others } \\
\text { (e.g., increase in self-understanding, more relax and better relationship with children) }\end{array}$ & 2 \\
A total of 8 participants had joined the self-help group and one became the mental health ambassador who provides peer counseling.
\end{tabular}

\section{Discussion}

This community-based outreaching initiative has made significant contributions to primary mental health in Hong Kong in four aspects: 1) our approach is a step forward than the previous ones such as the Depression Defeat Project (Leung \& Cheung, 2004), which is predominantly educational oriented. Having identified the highrisk groups in the communities and linking them up with mental health and social services, our programmes have strengthened the interface between the primary and secondary services in meeting people's mental health needs (Hartfield, Sharma, \& Ryan, 2007); 2) active contact with people of mental health needs in their familiar neighborhood has found to be effective to reach out the unreachable; 3) unlike the previous urban-based community mental health projects, our services have been extended to the rural communities; 4) the mental health ambassadors have been actively involved in helping and; 5) last but not the least, our project has illuminated the significant roles played by community social workers in primary mental health in this territory.

Within five years our team of social workers have successfully contacted a total of 2181 participants from urban and rural communities. Among these participants $20.6 \%$ were high-risk groups and their profile was as followed: the unemployed, the housewife, the widowed and divorced and those with lower educational attainment. Besides on-site advice and guidance, the participants were referred to counselling service, emotional management class, psychiatric service and job training. Over $88.1 \%$ and $85.7 \%$ of the participants reported increased knowledge in mental health and heightened awareness in this area respectively.

We have assessed the project outcome through documentation and data collections via multiple sources without any extra cost and resources. The results of the analysis have provided evidence to support the success of our project in accomplishing the objective of identifying the high-risk groups and linking them up with the services. We have trained the ambassadors to be part of our professional team.

Consistent with the results of previous studies (e.g., Wong et al., 2009; Ma et al., 2007), the results of our analysis indicate that the high-risk groups are people with fewer resources in society, who have faced with family problems and conflicts, financial pressure and have experienced job loss, separation and divorce, suggesting the plausible association of increased rate of depression with poverty (e.g., Bruce et al., 1991; Kessler et al., 2003), unemployment (Paul \& Moser, 2009; Lau, Ma, \& Wong, 2006), marital distress, separation and divorce (Kung, 2000). Housewives are found to be the high-risk group, which would probably be accounted for by the low social status of a housewife in society; the repetitive nature of their daily routine may have restrained their growth and development and may have made their life less meaningful. However, employment is a protective factor of better well-being.

Among these high-risk people, a few of them had been known to our mental health service but have dropped out from the service for different reasons such as dissatisfaction toward the insufficient professional care and time (usually not longer than 15 minutes per session) provided, constant change of doctors and the side-effects of the medication. Our social workers and the ambassadors linked them up with the self-help groups in the agency, encouraged them to share their stress and crises in the groups and contacted their families to provide timely assistance and help to them, if needed. The results gathered in the post-intervention phase suggested that the participants have benefited from the service referred. 
The results of our study have underscored the importance of social workers to contextualize stresses and difficulties faced by the high-risk groups in society, rather than to psychologize or pathologize them. Notably the CES-D scores of 79.4\% participants did not exceed 15, indicating that their mental condition was not severe enough to warrant immediate psychiatric assessment. However, their willingness to be referred for counselling service and emotional management class indicates their wish for professional service, in particular to help resolve their stresses from multiple sources: work, family and health and interpersonal relationships. Interestingly, the low-risk groups requested being referred to different services, suggesting that the value of our programmes in bridging the gap between the service providers and the service users.

Among the different means in reaching out the participants, our ambassadors have found to be useful in recruitment and engagement. Their experiential sharing has powerful effect of cultivating a strong sense of "we are in the same boat", thereby reducing the participants' sense of inadequacy, shame and stigmatization. More importantly, the ambassadors found the experience of helping fulfilling, meaningful and empowering, which in turn resulted in the enhancement of their self-confidence. Active participation of the ambassadors in the programmes is crucial in developing grass-root leaderships in the community and fostering mutual help and mutual support among people with mental health needs. However, the ambassadors did experience tensions and difficulties in helping participants with multiple problems, which called for timely assistance and advice from the social workers and in a few circumstances, from the supervisors as well. We plan to continue empowering these ambassadors, especially those having negative experience in mental health services, to join together for policy advocacy in future.

The challenge of our social workers is to assess the complexity of needs, often exacerbated by social problems, faced by people with mental health needs (Hartfield, Sharma, \& Ryan, 2007). This challenge has become driving force for the social workers to develop themselves professionally. We found it necessary to continue equipping our team of social workers with evidence-based mental health knowledge and skills in working with people with mental health needs as well as providing guidance and support to the ambassadors.

Despite its contributions, our study has its own limitations. The assessment on whether the high-risk groups have better cope with their tensions and difficulties after receiving the services was partly achieved since only 43 participants who have received the services (e.g., counselling service and psychiatric referral) had given their feedback in the post-intervention phase. The small sample has definitely weakened the generalizability of the findings. Besides, in reading the results of our analysis, we must be cautious that the CES-D scale was used as a means to engage and motivate the participants, rather than as a diagnostic instrument. Most importantly, with a lack of the matched control group in our research design, the participants' positive change may be attributable to factors (e.g., employment, improved family relationships) other than the services provided.

In view of the limitations of our study, we recommend that future investigators should adopt a panel study as a research design to assess if mental health condition of the high-risk groups has improved after receiving the services. Qualitative methods such as home visits and use of story should be employed to deepen our understanding of how the outreaching community-based approach has helped to eliminate their socio-cultural barriers in help seeking and link them up the services; the evidence gathered can help to refine and revise our programmes.

\section{Conclusions}

People with mental health needs are always ambivalent to seek help due to stigmatization of mental illnesses in society. Our initiative symbolises the collective effort of our social work team to reach out the seemingly unreachable in the community through strategic allying with the lay people, who have similar mental health needs and have successfully overcome their psychosocial barriers in help-seeking. With the organizational support of the agency, our team of social workers are able to launch this project, continuously equip themselves with updated mental health knowledge and skills, select and train the ambassadors to develop their ability and confidence to become true partners in helping.

The encouraging outcome of our initiative have confirmed our belief that community social workers have crucial roles to play to link up those with mental health needs to the service providers; in so doing the participants' level of depression can be reduced. However, there is no room for complacency. Our next initiative should shift from reducing the negative outcome in mental health to enhancing mental wellness (Chan, 2012). It is now time for us to learn more about our cultural resources such as the philosophy of Buddhism and mindfulness training (Hanh, 2007) and creatively utilize them to foster a peaceful and gratifying life for individuals, 
families and communities. Increasing research efforts would be strived to assess the effectiveness of these cultural resources in enhancing mental wellness in future.

\section{References}

Bruce, M. L., Takeuchi, D. T., \& Leaf, P. J. (1991). Poverty and Psychiatric Status. Longitudinal Evidence from the New Haven Epidemiologic Catchment Area Study. Archives of General Psychiatry, 48, 470-474. http://dx.doi.org/10.1001/archpsyc.1991.01810290082015

Caplan, G. (1964). Principles of Preventive Psychiatry. New York: Basic books.

Cattell, V. (2001). Poor People, Poor Place and Poor Health: The Mediating Role of Social Network and Social Capital. Social Science and Medicine, 52, 1501-16. http://dx.doi.org/10.1016/S0277-9536(00)00259-8

Census and Statistics Department (2011). Labour Force, Unemployment and Underemployment. http://www.censtatd.gov.hk/hong kong statistics/statistical tables/index.jsp?subjectID=2\&tableID=006

Chan, R. W. S. (2012). Positive Mental Health. Hong Kong Journal of Mental Health, 38, 3-4.

Chen, S. X., \& Mak, W. W. S. (2008). Seeking Professional Help: Etiology Beliefs about Mental Illness across Cultures. Journal of Counselling Psychology, 55, 442-450. http://dx.doi.org/10.1037/a0012898

Cheung, C., \& Bagley, C. (1998). Validating an American Scale in Hong Kong: The Centre for Epidemiological Studies Depression Scale (CES-D). Journal of Psychology, 132, 169-186. http://dx.doi.org/10.1080/00223989809599157

Chi, I., Yip, P. S., Chiu, H. F., Chou, K. L., Kwan, C. W., Conwell, Y., \& Caine, E. (2005). Prevalence of Depression and Its Correlates in Hong Kong's Chinese Older Adults. American Journal of Geriatric Psychiatry, 13, 409-416. http://dx.doi.org/10.1097/00019442-200505000-00010

Chung, K. F., \& Wong, M. C. (2004). Experience of Stigma among Chinese Mental Health Patients in Hong Kong. Psychiatric Bulletin, 28, 451-454. http://dx.doi.org/10.1192/pb.28.12.451

Hanh, T. N. (2007). The Art of Power. New York: Harper Collins Publisher.

Hartfield, B., Sharma, I., \& Ryan, T. (2007). Changing the Focus of Mental Health Team: A Study of One English Locality. Journal of Integrated Care, 15, 17-28. http://dx.doi.org/10.1108/14769018200700018

HKSAR Government (2011). LCQ11: Mental Health Services. http://www.info.gov.hk/gia/general/201105/18/P201105180167.htm

Hospital Authority (2011). Hospital Authority Mental Health Service Plan for Adults 2010-2015. Hong Kong: Hospital Authority.

Kessler, R. C., Berglund, P., Demler, O., Jin, R., Koretz, D., Merikangas, K. R. et al. (2003). The Epidemiology of Major Depressive Disorder: Results from the National Comorbility Survey Replication (NCS-R). Journal of the American Medical Association, 289, 3095-3105. http://dx.doi.org/10.1001/jama.289.23.3095

Kung, W. M. (2000). The Intertwined Relationships between Depression and Marital Distress: Elements of Marital Therapy Conducive to Effective Treatment Outcome. Journal of Marital \& Family Therapy, 26, 51-64. http://dx.doi.org/10.1111/j.1752-0606.2000.tb00276.X

Lau, Y. K., Ma, J. L. C., \& Wong, K. Y. (2006). Unemployment and Psychological Well-Being and Implications for Social Policy and Social Welfare Services: The Case of Hong Kong. Paper Presented in the 3rd Social Inclination and Social Indicators Conference, 1-2 September 2006, Institute of Sociology, Academic Sinica, Taipei. (in Chinese)

Lau, Y. K., Ma, J. L. C., Wan, P. S., \& Lai, L. Y. (2012). Work-Family Balance or Work-Family Conflicts: A Study of the Hong Kong Employees. Occasional Paper No. 224. Hong Kong: Hong Kong Institute of Asian-Pacific Study, The Chinese University of Hong Kong. (in Chinese)

Layard, R., Bell, S., Clark, D. M., Knapp, M., Meacher, M., \& Priebe, S. (2006). The Depression Report: A New Deal for Depression and Anxiety Disorders. London: London School of Economics. http://cep.lse.ac.hk

Lee, S., Lee, M. T. Y., Chiu, M. Y. L., \& Kleinman, A. (2005). Experience of Social Stigma by People with Schizophrenia in Hong Kong. British Journal of Psychiatry, 186, 153-157. http://dx.doi.org/10.1192/bjp.186.2.153

Legislative Council, Hong Kong SAR Government (2011). Updated Background Brief Prepared by the Legislative Council Secretariat for the Joint Meeting on 24 May 2011: Mental Health Services Provided by the Hospital Authority. www.legco.gov.hk/yr11-12/english/panels/hs/papers/hs_l.htm

Leung, E. Y., \& Cheung, H. K. (2004). The Defeat Depression Project: A Multilevel Mental Health Education Programme for Chinese-Speaking Communities in Hong Kong SAR. In S. Saxena, \& P. J. Garrison (Eds.), Mental Health Promotion Case Studies from Countries (pp. 21-24). Geneva: World Health Organization.

Leung, S. S. K., Martinson, I. M., \& Arthur, D. (2005). Postpartum Depression and Related Psychosocial Variables in Hong Kong Chinese Women: Findings from a Prospective Study. Research in Nursing \& Health, 28, 27-38.

http://dx.doi.org/10.1002/nur.20053 
Li, S. P., Chan, C. W. H., \& Lee, D. T. F. (2002). Helpfulness of Nursing Actions to Suddenly Bereaved Family Members in an Accident and Emergency Setting in Hong Kong. Journal of Advanced Nursing, 40, 170-180. http://dx.doi.org/10.1046/j.1365-2648.2002.02359.x

Nayar, K. R., Kyobutungi, C., \& Razum, O. (2004). Self-Help: What Future Role in Health Care for Low and Middle-Income Countries. International Journal of Equity in Health, 3, 1-10. http://www.equityhealthj.com/content/3/1/1 http://dx.doi.org/10.1186/1475-9276-3-1

Ma, J. L., Wong, T. K., Lau, Y., \& Pun, S. (2007). Family Health of Hong Kong Chinese Families and the Link to Individual Well Being. Occasional Paper No. 188, Hong Kong: Hong Kong Institute of Asia-Pacific Studies, The Chinese University of Hong Kong. (in Chinese)

Ma, J. L. C., Wong, T. K. Y., Lau, Y. K., \& Lai, L. Y. (2011). Parenting Stress and Perceived Family Functioning of Chinese Parents in Hong Kong: Its Implications for Social Work Practice. Asian Social Work and Policy Review, 5, 160-180. http://dx.doi.org/10.1111/j.1753-1411.2011.00056.x

Paul, K. I., \& Moser, K. (2009). Unemployment Impairs Mental Health: Meta-Analyses. Journal of Vocational Behaviour, 74, 264-282. http://dx.doi.org/10.1016/j.jvb.2009.01.001

Radloff, L. S. (1977). The CES-D Scale: A Self-Reported Depression Scale for Research in the General Population. Applied Psychological Measurement, 1, 385-401. http://dx.doi.org/10.1177/014662167700100306

Scheyett, A. (2005). The Mark of Madness: Stigma, Serious Mental Illnesses and Social Work. Social Work in Mental Health, 3, 79-97. http://dx.doi.org/10.1300/J200v03n04 05

Sousa, L., Ribeiro, C., \& Rodrigues, S. (2006). Intervention with Multi-Problem Poor Clients: Towards a Strengths-Focused Perspective. Journal of Social Work Practice, 20, 189-204. http://dx.doi.org/10.1080/02650530600776913

Siu, S. W., Wan, P. S., \& Wong, T. K. Y. (2011). Facing and Responding to Economic Crisis: Highlight of 2009 Survey in Hong Kong and Taiwan. Paper Presented at the 2011 Taiwan-Hong Kong Sociology and Social Image Conference, 11-12 March 2011, Institute of Sociology, Academic Sinica, Taipei, Taiwan and Hong Kong Institute of Asia-Pacific Studies, The Chinese University of Hong Kong. (in Chinese)

Tseng, W. S., Lin, T. Y., \& Yeh, E. K. (1995). Chinese Societies and Mental Health. In W. S. Tseng, T. Y. Lin, \& E. K. Yeh (Eds.), Chinese Societies and Mental Health (pp. 3-18). Hong Kong: Oxford University Press.

USA Public Health Service, Office of the Surgeon General (1999). Mental Health: A Report of the Surgeon General. Bethesda, MD: National Institute of Mental Health.

Wang, P. S., Lane, M., Olfson, M., Pincus, H. A., Wells, K. B., \& Kessler, R. C. (2005). Twelve Month Use of Mental Health Services in the United States. Archives of General Psychiatry, 62, 629-640. http://dx.doi.org/10.1001/archpsyc.62.6.629

Wong, S. Y. S., Lau, C. H. J., Wong, E. M. C., Chung, V. C. H., Lo, S., Goggins, W., \& Griffiths, S. M. (2009). Geographical and Household Variation in Health-Related Quality of Life in Hong Kong. Health and Place, 16, 315-320. http://dx.doi.org/10.1016/j.healthplace.2009.10.015

Yang, L. H. (2007). Application of Mental Illness Stigma Theory to Chinese Societies: Synthesis and New Directions. Singapore Medical Journal, 48, 977-985.

Ye, S., Leung, T. T. F., \& Mok, B. H. (2011). Measuring Mutual Help Willingness and Criteria among Hong Kong People: Confirmatory Factor Analyses. Social Indicators Research, 103, 119-130. http://dx.doi.org/10.1007/s11205-010-9700-x 